\title{
Trauma Africa
}

Victor Y. Kong'.

\section{The Experience.}

"Major Trauma. Dr. Kong, please come to the Trauma Unit immediately. Dr. Kong, please come to the Trauma Unit immediately." Even though I have been working at Edendale Hospital as a trauma registrar for over a year, whenever I hear this announcement over the hospital intercom system, my heart beats just a little faster than normal. When I first arrived at Edendale my colleagues told me that the adrenaline rush I would experience after being called out to attend a new emergency would decrease over time, and indeed they were right. However, it is also true to say that on some occasions more than others, it is still felt more strongly than ever.

On one particular night, as I made my way towards the resuscitation area in response to yet another major 'trauma call', I was greeted by the most enthusiastic of paramedics, who was drenched in blood to the extent you would expect to see on the television drama Trauma. As we walked at a brisk pace, he started to tell me about the new case, "We have an unknown male with multiple CSWs to the abdomen, no recordable $\mathrm{BP}$, and he is restless and hypothermic."The paramedic reported that the patient had been chased by the police and had been shot several times after having attempted a hijacking. In medical school there was a saying

Figure 1. Typical Friday night scene ouside the trauma unit at Edendale Hospital, South Africa.

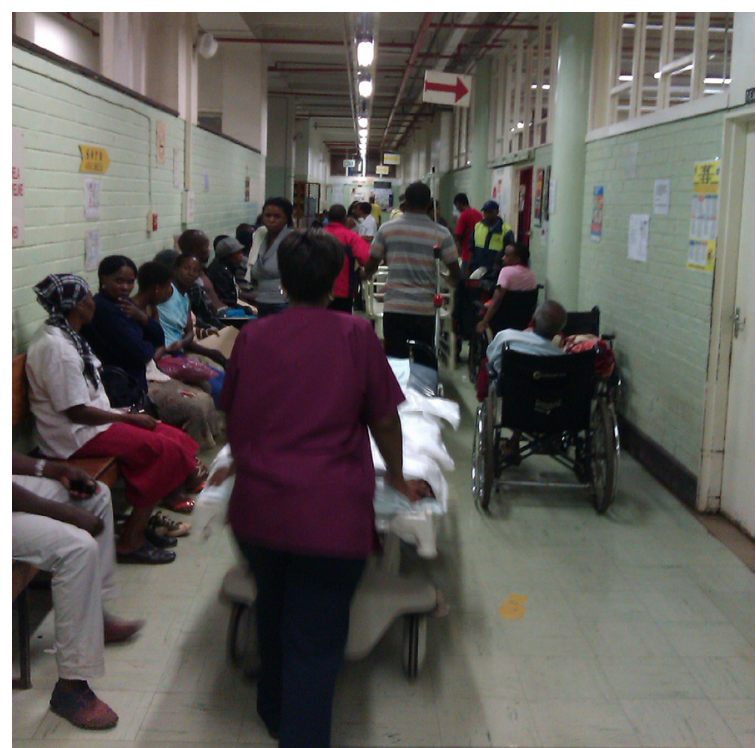

which went, "common things are common", and in some parts of South Africa crime is so rampant it is almost a daily occurrence. Faced with the prospect of treating this new 'unfortunate' victim, I tried to remain calm, especially when I saw that my best interns were struggling to obtain intravenous access. The stakes were high and everyone was watching and waiting for some sort of miracle to happen. The ATLS training doctors receive can sometimes give the impression that everything is supposed to work on the first attempt. For example, the ${ }_{14} \mathrm{G}$ Venflon is supposed to somehow just slip into the antecubital fossa, without a hitch. Training is supposed to prepare doctors to manage these cases without even thinking about it. However, the golden rule of being a surgeon is always to have a Plan B (or even a Plan C) in these sticky situations. It takes a lot of discipline, training and experience to maintain a calm and composed exterior. When the resuscitation 'algorithm' began to tick for this patient, it became immediately clear to me that he needed an operation in order to survive. Without any intention of trying to impress the team, I quickly inserted a high flow femoral line and managed to start infusing a litre of Hartman's solution hanging by the patent's trolley. As the pump pushed fluid further into his vein, the rest of the resuscitation continued like clockwork. Then, when the patient was transfused, warmed and mostly awake, I signal led to the interns that it was time for them to move onto the next stage, and they knew exactly what I meant. one would come with me to the operating theatre, whilst the others would 'hold the fort' on the front line until I had finished with the patient. Interns seldom complain when I am on call because they know exactly what to expect and what is expected, which is to keep the patient alive by whatever means.

Soon I was scrubbing up and donning that familiar blue gown in order to perform yet another trauma laparotomy. This was my seventh trauma laparotomy of the shift, and, in all honesty, I could hardly keep my eyes open because I had been operating in theatre literally all day and night. Just as I started to think, 'When will this shift ever end?' suddenly the adrenaline kicked in once more and I got even more excited. As cliché as it sounds, knowing that I can make a difference acts as a great motivator. More importantly, everything had been set up well by the team,
What is a Registrar? Registrar is the equivalent of Resident in North America. It means a surgeon still in training.
About the author Victor Kong is a Surgical Registrar at Edendale Hospial, Pietermaritzburg, South Africa. He studied Medicine at University of Otago, New Zealand and currently is can didate to PhD at University of Natal.

Submission: 2012, March 8 Accepted: 2012, May 19. Process: Peer-Reviewed.

\footnotetext{
${ }^{1}$ Surgical Registrar, Trauma Unit, Edendale Hospital, Pietermaritzburg, South Africa.

Correspondence

Dr. Victor Kong

Address: Trauma Unit, Edendale Hospital, Pietermaritzburg, South Africa.

E. mail: victorywkong@yahoo.com
} 
including the cell saver, fluid warmer and all the equipment needed for a trauma operation. Then, the Scrub Nurse greeted me with an ironic, "San'bonna" (Hello in Zulu) Dr. Kong - welcome back."

Without hesitation, I proceeded to follow a well practiced drill. I opened the abdomen in no time at all, and, as expected, blood was everywhere. It is strange that sometimes, for this operation, a surgeon's anxiety level seems to be inversely proportional to the number of swabs available to pack the abdomen. If swabs run out on a typically busy 'end-of-month-payday-Friday night' the next best option is to use sterile drapes, or whatever is available in the vicinity. All the basic manoeuvres I had been taught so well by my trauma consultants now came in handy. of course, I thought, it is their shoes I ultimately want to fill, but for now I packedthe liver, the spleen was out, the stomach was repaired, and I made sure that the ends of the small bowel were stapled off properly. Just before the anaesthetist was about to tell me how much time had been wasted (as he always does), I managed to temporarily close the abdomen with a Bogota bag, and not one made in South America, but one made in Edendale hospital! I was in 'damage control mode' in order to keep the patient alive to fight another day. Again, it had been another exhilarating night. Nothing is more exciting than saving a life - this is why I became a surgeon.

Deciding to work as a Trauma Registrar at Edendale Hospital was one of the best career decisions I ever made. The trauma seen here is almost unimaginable in its volume, and it includes gunshots, stab wounds, and road traffic accidents, among many other things. At times you feel as if you are standing next to a surgical conveyer belt carrying extreme human suffering. However, on a positive note, most of the victims are young and fit and they usually have an extremely good outcome if their injuries are treated early. At
Edendalel get opportunity to hone my practical skills in a multitude of emergency procedures, including some that are seldom performed elsewhere in the world. No longer do I have to experience frustration in trying to compete with five other colleagues simply to insert a chest drain (the maximum any registrar has done in one shift was said to be around thirty!). Neither do I have to wait over six months just to be able to insert a central line because my anaesthesia colleagues 'need the experience for their log books'. Performing a venous cut down, cutting a surgical airway, or decompressing a tension pneumothorax, are some procedures you have to performroutinely in order to keep a patient alive. Just as a new intern is expected to be able to perform a phlebotomy as a standard skill, every trauma registrar at Edendale is expected to master complex skills quickly, and as routine. You simply have to be prepared to deal with whatever is presented to you, and, often, thepeople presented here on a daily basis are the sickest trauma patients. The most common operation performed at night is a trauma laparotomy, but more often, just like meeting a trajectory of bullets, it is difficult to know what type of case to expect next. From dealing with a minor serosal tear to treating a massive torrential haemorrhage which requires a combined laparotomy and thoracotomy, the cases seen here make life extremely exciting. Once, I vividly remember having to insert a chest drain (for a patient with massive haemothroax who was in extremis) in the corridor outside of the operating theatre when there was no more space left inside. Also, I remember performing an emergency cricothyroidotomy in a lift when it became stuck between floors. Luckily though, at Edendale the trauma consultants are among the best in the world and they are always available to help.

With trauma, no two patients are the same and everything appears as new. When I first performed a front room thoracotomy on a stab victim, I remember that when my
Figure 2. Entrance - Edendale Hospital.

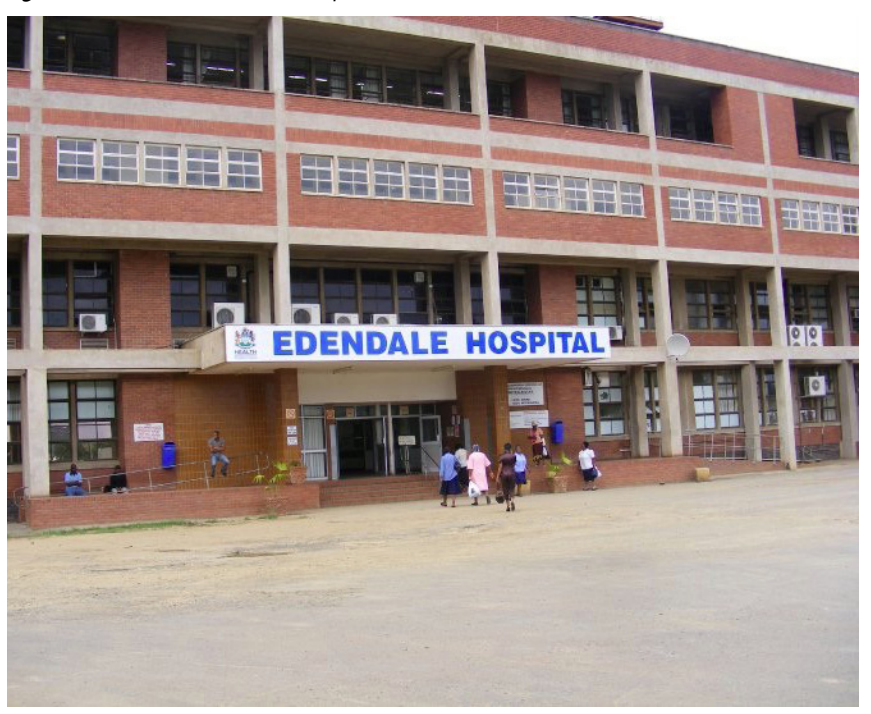

Figure 3. Emergency room thoracotomy for penetrating cardiac injury, traumatic arrest on arrival.

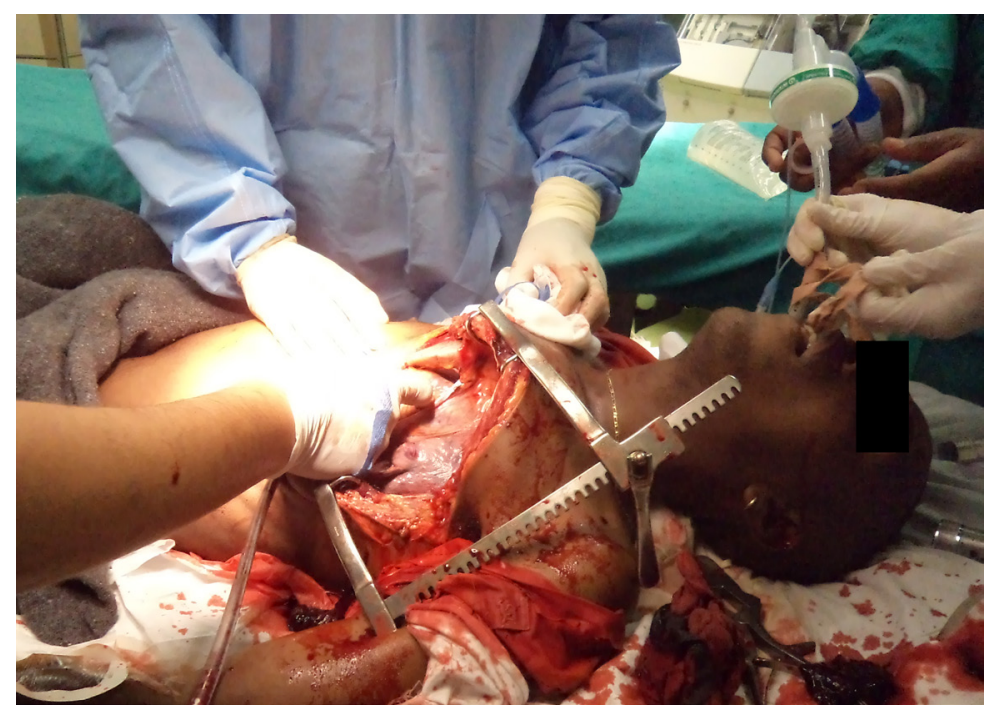


hands were deep in his chest messaging his heart, I had the sensation that my own heart was beating far more vigorously than the pace at which I was trying to massage the patient's. However, emergency cases are what keep me, and many others, going through sleepless and lonely nights. At the end of the day, South Africa is one of the most dangerous countries in the world. When one of my consultants asked me why I had left a comfortable life in Dublin for a life in South Africa, I could not think of a perfect answer. Partly it was because I felt an urge to expand my horizons, and partly it was due to my sense of competition; I wanted to train myself to be as good as, or better than, my colleagues. Mostly though, it was in order to follow a desire that had been in my heart for many years, and to do this it seemed worth the risk. There are not many things worth risking one's life for, but to quench a thirst for a different type of surgical experience seemed worth the risk. Trauma surgery is definitely not for the faint hearted, but the experience I have gained at Edendale is invaluable; working at Edendale is the once-in-a-lifetime experience. I have matured far beyond my own expectations, and I have seen human suffering at the extreme end of the spectrum. I have learnt to become more compassionate for the less fortunate, and I have seen first-hand what extreme poverty means. Most importantly, I have learnt how to survive.

It takes a lot to try to remain strong in what is, at times, a potentially dangerous working environment, especially if you want to become the best surgeon. Sometimes, I wonder what life would have been like if I had not left for South Africa. At least I would not be hearing that one of my colleagues at another hospital has been stabbed to death by a patient. Or even worse, witnessing the distress of one patient shooting another patient in front of my eyes, an experience that left me paralysed with fear for days. However, it is more likely that I would be wondering what I was truly missing in my surgical career, which is the sense of excitement of trauma surgery. When I was writing up the operative notes for the gunshot victim, I recalled that only a short while ago another patient had been shot on the hospital premises right next to the ATM machine, and then, for a split second, I could have sworn I heard the sound of faint gunshots just outside of the hospital. Perhaps this was just cynicism, and tiredness at the end of a shift, but I reasoned that it would be far stranger not to be alert to the potential for danger after having experienced working at Edendale for over a year. However, before I even had time to let my imagination wonder further, the familiar voice on the hospital intercom system announced, "Major trauma. Dr. Kong, please come to the Trauma Unit immediately.' So, once again I made my way back to the Trauma Unit. This time, on my way back my anaesthetist approached me and said, "I hope you realise that your colleague has just booked in another three patients who all need trauma laparotomies. Are you still doing them or what?"As I was coming to the end of a long shift, it would have been easy
Figure 4. A: Patient with a stabbed abdomen, with bowel evisceration. B: Patient with multiple GSW (gunshot wound) to torso.

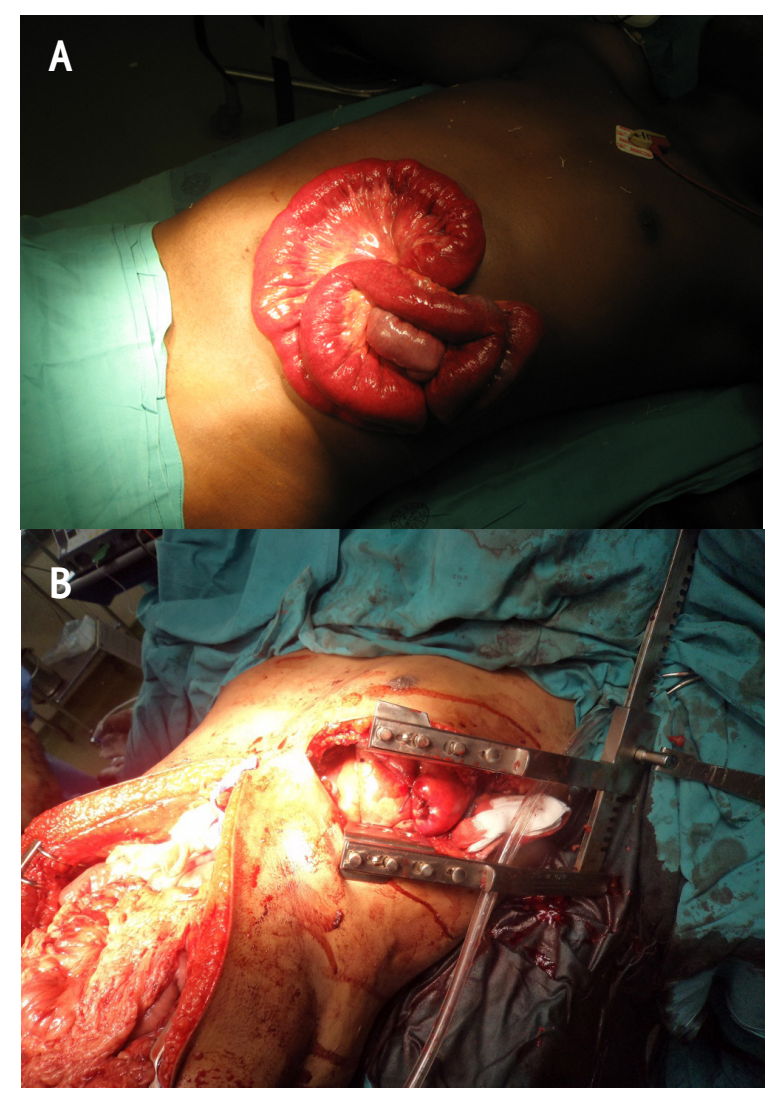

Figure 5. Me prior to performing a splenectomy (blunt trauma victum).

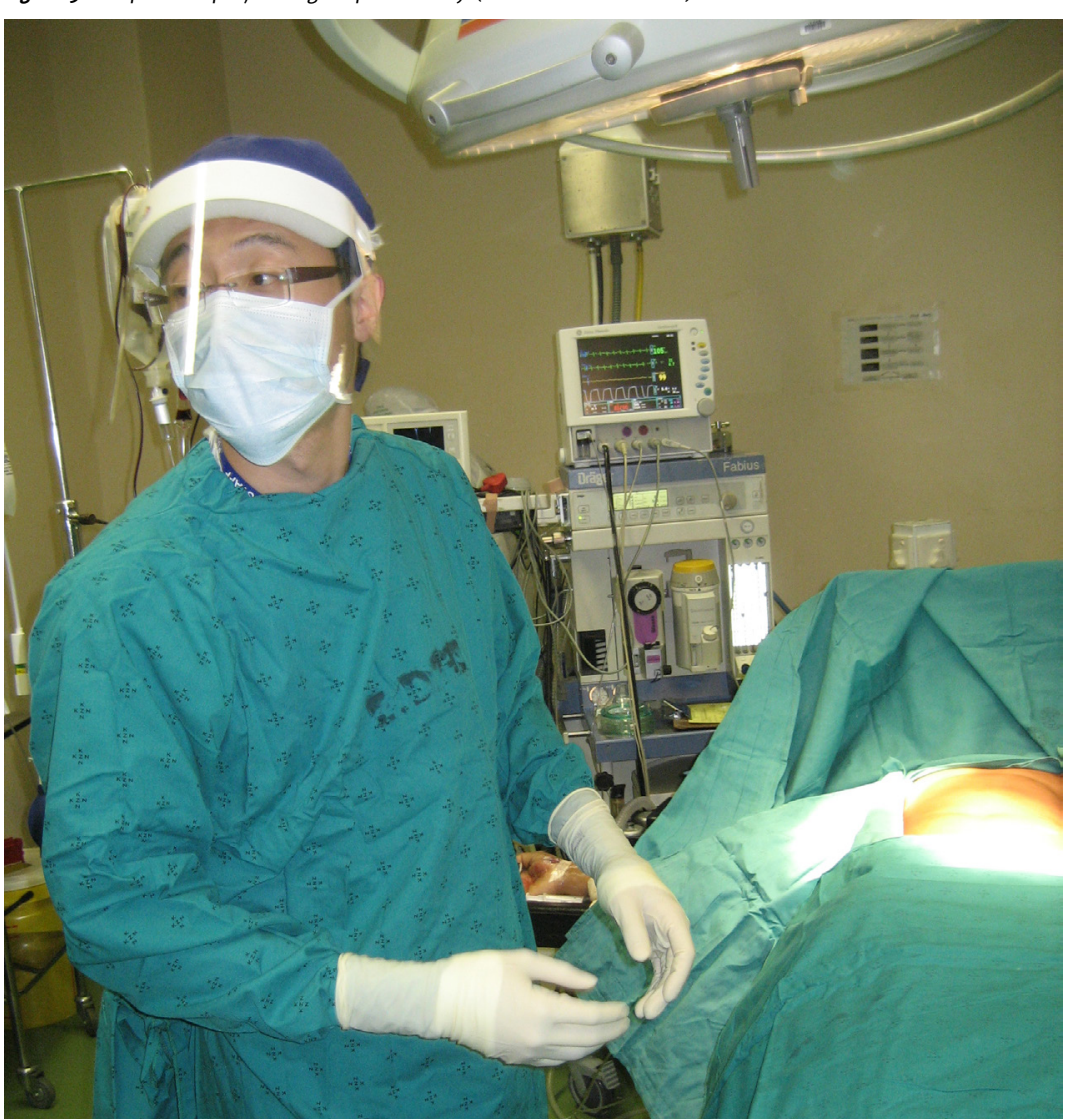


to respond sharply to this type of comment, but instead, I composed myself once again and replied in a calm but assertive manner, "Yes I am, but not now. There is another trauma thoracotomy coming in first." 